\title{
CHARITY AND THE REITERATION PROBLEM FOR ENTHYMEMES
}

\author{
Dale Jacevette, The Pennsylvania State University
}

Keywords: Charity; principle of charity; charity rankings; enthymeme; sound argument; (conditional) reiteration; reiteration problem (for enthymemes); valid inference.

\begin{abstract}
Any enthymeme can be made logically valid by adding as a suppressed premise a conditional that reiterates the argument's stated content and inferential structure in if-then form. We cannot blanketly prohibit reiteration to avoid this sort of trivialization, because some enthymemes legitimately require completion by reiterative conditionals. The solution proposed here is to allow reiterative expansions, but to rank them, other things being equal, as less charitable than nonreiterative expansions. Reiterative expansions can then be chosen as the most charitable only when all nonreiterative expansions have been eliminated for independent reasons. This pluralistic model encourages experimentation with a number of different permissible expansions in evaluating enthymemes, from the least controversial or problematic to the most trivializing and the least charitable.
\end{abstract}

Résumé: On peut rendre n'importe quel enthymème logiquement valable en y insérant une phrase conditionelle dont l'antécédent réitère toutes ses prémisses et dont le conséquent répète sa conclusion. Nous ne devons pas interdire ces réitérations conditionelles dans le but d'éviter pareille banalisation, car certains enthymèmes les requièrent légitimement pour être complétés. La solution proposée ici est de permettre ces réitérations, mais, toutes choses égales, de classer les interprétations qui inclues une telle réitération sera choisie comme plus charitable que celle qui l'exclue seulement si des raisons indépendantes justifient cette exclusion. Cette approche pluraliste encourage l'examen d'une gamme de réitérations possibles lorsqu'on évalue des enthymèmes: allant des moins controversés ou problématiques aux plus banals et moins charitable.

\section{The Concept of Charity}

The principle of charity enjoins us to critically evaluate an argument only after we have presented it in the most favorable light under the inferentially and epistemically strongest and most reasonable interpretation. ${ }^{1}$

This is not only a just but a prudent policy for interpreting and criticizing another's reasoning. The author of an enthymeme or incompletely stated inference in particular preconditionally deserves our unprejudiced respect as a competent thinker; or, as we might also say, deserves to have his or her arguments evaluated as generously as we would hope to have our own understood. For reasons of style, convenience, or persuasion, many good arguments are expressed enthymematically, and there is no point in criticizing a certain enthymeme as deductively invalid because of gaps in its incompletely stated assumptions and conclusions. Rather, we should give the argument every benefit of the doubt, reconstructing it wherever possible as the most compelling valid inference it might be intended to express before passing judgment on its overall acceptability. 


\section{Dale Jacquette}

To criticize arguments charitably contributes to an enlightened spirit of openminded inquiry which should be promoted as nurturing the best climate for the free pursuit and discovery of truth. But at bottom an appeal to the principle of charity is truly justified only if there is a greater probability that the authors of enthymemes are usually capable of and intend to communicate good rather than bad arguments. This is true in part because on the whole arguments in whose reasoning we are likely to be seriously interested (not just as classroom or textbook specimens) are preselected by our largely reliable intuitive sense that they are trying to convey something intelligent. I personally share this expectation, so I am inclined on balance to proceed charitably in criticizing enthymemes. I think that most enthymemes can be nontrivially expanded as logically valid inferences, which may yet be subject to other kinds of criticisms. If we do not suppose most of these incompleted stated arguments to be at least logically circumspect after charitable reconstruction, then we exclude from consideration an enormous body of intuitively reasonably deduced knowledge. Thus, there is an epistemic as well as a moral motivation toward adopting some version of the principle of charity.

I shall not try to further define the concept of charity or formulate more exactly the particular version of the principle of charity I think we should follow. For my purposes it is enough if for whatever reason we generally regard it as in some sense preferable to critically evaluate enthymemes only after we have at least decided what propositions we would need to add to make them logically valid. Of course, there is more to charitably expanding an enthymeme than reinterpretating it as a valid inference. Here I shall only explicate and defend the advantages of a particular model of charitable evaluation for deductively valid enthymeme expansions. Beyond this, I shall not propose general techniques for producing charitable reconstructions of enthymemes. The concept of charity to which the model is meant to apply is nevetheless supposed to be consistent with the most commonly recognized features of charitable criticisms. I am primarily interested in describing charitably valid expansions of enthymemes as admitting of degrees of charity, and explaining how structurally we might try to compare whatever expansions we may admit as more or less charitable. The goal is to rank expansions so as to pick the most charitable to criticize as the best most reasonable statement argument the author may have intended, according to the criteria I shall advance.

\section{The Reiteration Problem}

The principle of charity minimally entails among other things that in assessing an enthymeme we should as a rule try to expand the argument by interposing as implicit assumptions or conclusions only the most plausible propositions minimally required to complete the argument as a valid, sound, nonredundant, noncircular inference. ${ }^{2}$

There is, however, despite the virtues of criticizing only the most charitable valid reconstructions of enthymemes, a difficulty encountered in applying the principle. The problem is that if we choose to do so we can expand any enthymeme trivially as a valid inference simply by adding a conditional assumption that takes a conjunction of the argument's stated premises as antecedent and a conjunction of its stated conclusions as 
consequent. This renders the validity requirement for charitable expansions otiose by transforming even the most intuitively invalid inferences into deductively valid expansions. What then is the point and where is the charity in completing an intuitively invalid enthymeme as a valid expansion, when it is possible to guarantee valid reconstructions of any and every enthymeme so cheaply that no enthymeme fails in this limited sense to have at least a charitably valid expansion?

Consider the following intuitively invalid argument as an enthymeme to be expanded according to the principle of charity:

1. Roses are red.

2. Violets are blue.

By the principle of charity, there will always be a reconstruction of any sequence of propositions as a valid argument in modus ponendo ponens. For the above inference, the valid expansion (using standard bracketing and alphabetical labeling to indicate suppressed assumptions or conclusions, and asterisks to mark reiterative assumptions) looks like this:

1. Roses are red.

[a*.If roses are red, then violets are blue.]

2. Violets are blue.

The possibility of satisfying the principle of charity in this uninteresting way has been called the reiteration problem. ${ }^{*}$ The objection is that such a facile method permits the reconstruction of any enthymeme whether intuitively valid or invalid as a valid inference. We need only interpose a conditional that reiterates the content and inferential structure of the entire original enthymeme in if-then propositional form as a suppressed assumption. This trivializes the principle of charity as a constraint on the reconstruction of enthymemes, because it guarantees deductive validity far too easily. There is no enthymeme whatsoever that cannot be reconstructed by reiteration as a logically valid inference in naive compliance with the validity requirements of charitable expansion. ${ }^{5}$

The problem is not solvable $a d$ hoc by prohibiting reiteration. Some enthymemes legitimately require completion by reiterative conditionals. Nor is it enough to rely on charitable reconstructions as sound and noncircular. Many reiterative expansions of enthymemes involve the interposition of true assumptions, and there is nothing inherently circular about reiterative expansions. Some reiterations may involve false assumptions, as when an enthymeme's stated assumptions are true, but at least one stated conclusion is false. But in the present case, where it is true that violets are blue, the reiterative standard material conditional for this enthymeme, that if roses are red then violets are blue, is also true. The soundness of charitable expansions furthermore cannot be universally applied to block valid reconstruction by reiteration, since soundness fails whenever an enthymeme to be charitably expanded already contains at least one false stated assumption or conclusion. ${ }^{6}$

It might be thought that we could avoid trivializing the charity principle by in- 


\section{Dale Jacquette}

voking a psychological estimate of the enthymeme author's intent. On these grounds, the above argument might either be justified in reiterative expansion as what the author is likely to have had in mind, rejected as hopelessly invalid, or reconstructed in another way by the interposition of more imaginative nontrivializing suppressed assumptions. This approach, unfortunately, cannot provide a general solution to the problem of charitably reconstructing enthymemes. ${ }^{7}$ We typically have no direct access to what an author may have intended in advancing an enthymeme, and often we do not even know who the author of an enthymeme is or anything about the author's beliefs or background that would provide a clue as to how an argument might reasonably be expanded. The best we can do, except where collateral external sources happen to exist, is vicariously to interpose those assumptions or conclusions we ourselves might imagine wanting to assert if we were trying to offer the argument. But, since this is one of the guidelines we might follow anyway in applying the principle of charity, nothing is gained by describing the expansion of an enthymeme as an effort to second-guess an author's unspoken intentions. ${ }^{8}$

There seems in short to be no fully satisfactory autonomic basis for permitting some reiterations and forbidding others, and no solution to the phenomenological limitations by which third-person interpretors are excluded from knowing what suppressed premises an enthymeme author may have 'had in mind'.

\section{Charitable Expansion of Dumas' Enthymeme}

As a basis for comparison, let us now consider how the valid expansion of enthymemes is ideally supposed to work. For this purpose, I shall introduce the incomplete expression of an inference from the literature of romantic fiction. The argument, which I shall refer to as the tulip syllogism, appears in Alexandre Dumas' (1850) novel, The Black Tulip. Dumas writes:

[Van Baerle] belonged to that...school who took for their motto in the seventeenth century the aphorism uttered by one of their number in 1653 , - "To despise flowers is to offend God."

From that premise the school of tulip-fanciers, the most exclusive of all schools, worked out the following syllogism in the same year: -

"To despise flowers is to offend God.

"The more beautiful the flower is, the more does one offend God in depising it.

"The tulip is the most beautiful of all flowers.

"Therefore, he who despises the tulip offends God beyond measure."

By reasoning of this kind, it can be seen that the four or five thousand tulip-growers of Holland, France, and Portugal, leaving out those of Ceylon and China and the Indies, might, if so disposed, put the whole world under the ban, and condemn as schismatics and heretics and deserving of death the several hundred millions of mankind whose hopes of salvation were not centred upon the tulip. ${ }^{9}$

The first part of the argument is explicit rather than enthymematic. A literal transcription can be given almost directly from this translation of Dumas' story. Here we have:

1.To despise flowers is to offend God.

2.The more beautiful a flower is, the more one offends God by despising it. 
3.The tulip is the most beautiful of all flowers.

4.Whoever despises tulips offends God beyond measure.

In this form, the argument is obviously invalid. The conclusion is too strong to be supported by the assumptions. A reiterative reconstruction of the argument introduces another, conditional, assumption as implicit or suppressed. The assumption states:

[a*. If to despise flowers is to offend God, and if the more beautiful a flower is, the more one offends God by despising it, and if the tulip is the most beautiful of all flowers, then whoever despises tulips offends God beyond measure.]

There are at least two choices for a charitable nonreiterative reconstruction. We can nonreiteratively strengthen the assumptions, or nonreiteratively weaken the conclusion. If we are to strengthen the assumptions, then we might interpose an implicit nonreiterative premise to the effect that:

[a. The most beautiful flower is beautiful beyond measure.]

Without the equivalent of this proposition, the argument as stated leaves open the possibility that God might yet be measurably offended by those who despise tulips, the most beautiful flowers. The implicit assumption in [a], required to sustain the stated conclusion of the inference, arguably is internally conceptually inconsistent, since the beauty of the most beautiful flower might be thought ordinally measurable by comparison with those less beautiful than it. The fact that the most beautiful flower is the most beautiful might be construed as the nonincremental measure of its beauty. Then again, all three of the stated assumptions in the first part of Dumas' argument are implausible anyway. But we need not question the argument's soundness any further to consider the alternative variably charitable strategies available for expanding it as a valid inference.

The second charitable reconstruction of the first part of Dumas' argument involves weakening the stated conclusion. This goes a bit beyond the responsibitity expected of most enthymeme expansions. Yet it falls within the charge of charitable reconstructions to interpret a conclusion as overstated for purposes of emphasis or dramatic effect, and to restate the conclusion so that it follows logically from a reasonable reconstruction of the stated assumptions. The term 'beyond measure' is an indication of the kind of hyperbole one often encounters in a proof's finale as a way of getting attention, but which the reader or listener is not necessarily meant to take literally. Another way of understanding the inference is therefore to interpret the stated conclusion by revising it as validly inferrable from the stated assumptions. The most likely reformulation of Dumas' stated conclusion so as to produce a valid inference is to substitute for proposition (4) this somewhat diluted form:

[4'. Whoever despises tulips offends God to the highest degree possible within the range of degrees to which God can be offended by those who despise flowers.]

The revised conclusion is consistent with the possibility that we might offend God to higher degrees in other ways than by despising flowers. But the revision preserves the essential assumption of the original argument by which a direct proportion 


\section{Dale Jacquette}

is supposed to hold between the degree of a flower's beauty and the degree of offense God takes in its being despised.

This approach is arguably more charitable in avoiding the attribution to Dumas of the apparently inconsistent or otherwise meaningless and unintelligible concept of the beauty of the most beautiful flower as beautiful beyond measure. To say that the most beautiful flower is beautiful beyond measure appears a far more general claim than that the most beautiful flower is, for example, beyond price. It implies not only that we cannot assign any particular units of value to the flower's beauty, but that the beauty of the most beautiful flower is beyond our ability to recognize or assign to it any aesthetic value whatsoever to mark our comparison of its beauty with the beauty of other less beautiful flowers. Otherwise, at the loss of contrast essential to his syllogism, Dumas might equally remark the lack of any exact measure for the beauty of sweetpeas or dandelions. Yet it is the problematic overstated conclusion in Dumas' enthymeme about God's being offended beyond measure that challenges charity in my diagnosis by making the inference deductively invalid. ${ }^{10}$

The same implausibility threatens if the validity of the inference is secured by substituting for the original assumption (3) this strengthened counterpart:

[3'. The tulip is a flower beautiful beyond measure.]

This restores the original undiluted conclusion. But it does so in much the same way as [a], despite avoiding the appearance of internal inconsistency. The difficulty now is that it is sheer unconvincing hyperbole and poetic enthusiasm to say that the beauty of a tulip is beyond all measure. What can it mean, other than as an expression of rapturous aesthetic delight, to say that the beauty of tulips is beyond measure? The statement might be understood as claiming that the beauty of tulips is so much greater than the beauty of other flowers as to be incomparable. But then the measure of a tulip's beauty, for those who share this high opinion of its qualities, is precisely that it is preferable to such an extent over and above that of all other flowers. If the beauty of tulips is beyond measure even in this loose sense, then it may not be intelligible to speak of tulips as beautiful at all. It would be as unintelligible as speaking of the greatest number, in the sense of a number great beyond all numbering. If the immeasurability of the tulip's beauty on the other hand merely expresses the idea that there is no objective metric standard for its subjective aesthetic qualities, then the same might be said of the beauty of any flower.

We have now examined three different ways of expanding the first part of Dumas' argument. The second part is even more interesting, and even more enthymematic. Here most of Dumas' assumptions are implicit or suppressed, and only the conclusion is explicitly stated. The conclusion of the second part of the argument, referring back to the first part, is alleged to follow by 'reasoning of this kind'. Dumas thereby suggests that the second part of the argument represents a continuation of or analogy with the first part. The conclusion can be formulated as saying that:

5.Those who cultivate tulips are entitled to put under ban and condemn as schismatics and heretics deserving of death all those who do not base their salvation on the cultivation of tulips.

It is this part of Dumas' inference that is the most problematically enthymematic. 
Enormous gaps in the reasoning we may be asked to bridge make it difficult to supply the missing assumptions that take us directly or by analogy from the previous argument to this startling proposition. The context suggests that Dumas deliberately exaggerates the importance tulips have for some of the characters in his novel, and that by this outrageous inference he means in particular through a comparison with religious intolerance to offer a reductio ad absurdum of Van Baerle's infatuation with the tulip. This does not lessen the importance of charitably reconstructing Dumas' enthymeme; on the contrary, in order to appreciate the argument's comic implications in his narrative, we need to see just what inference is being expressed.

As before, the enthymeme can be expanded reiteratively or nonreiteratively. Reiterative expansion from (1)-(4) to (5), with provision (in brackets) for previously considered interpositions [a], [a* $],\left[3^{\prime}\right]$, and [4'], has this form:

$\left[\mathrm{b}^{*}\right.$. If to despise flowers is to offend God, and if the more beautiful a flower is, the more one offends God by despising it, and if the tulip is the most beautiful [beautiful beyond measure] of all flowers, and if whoever despises tulips offends God beyond measure [whoever despises tulips offends God to the highest degree possible within the range of degrees to which God can be offended by those who despise flowers], then those who cultivate tulips are entitled to put under ban and condemn as schismatics and heretics deserving of death all those who do not base their salvation on the cultivation of tulips.]

The method is to make the added assumption explicitly reiterative by conjoining the enthymeme's stated assumptions and conclusions as the antecedent and consequent of a conditional which is then introduced as an implicit or suppressed assumption in the argument's expansion. The nonreiterative reconstruction of the argument on the contrary requires a more imaginative consideration of propositions that span the enthymeme's inference gaps.

One way of linking the conclusion in (5) with the previous argument structure is to insert the following implicit assumption:

[b. Those who cultivate tulips (in Holland, France, Portugal, etc. not despise tulips.]

[c. Those who do not cultivate tulips (in the rest of the world) despise tulips.]

[d. Those who despise tulips do not base their salvation on the cultivation of tulips.]

[e. Those who do not offend God beyond measure [to the highest degree possible within the range of degrees to which God can be offended by those who despise flowers] are entiled to put under ban and condemn as schismatics and heretics deserving of death all those who offend God beyond measure [to the highest degree possible within the range of degrees to which God can be offended by those who despise flowers].]

A detailed reconstruction of this sort illustrates the extraordinary leap to be made in extending the first part of the argument to the absurd conclusions Dumas draws in the second part. What necessary connection can there be between persons generally 


\section{Dale Jacquette}

despising or not despising tulips, and, assuming they have the opportunity, choosing to cultivate them or not? What of those who cultivate tulips purely for profit, with no appreciation of their beauty, and who despise them as they might any cash crop? What of persons who dearly love tulips, but who, for reasons of health, climate, or economy, are unable to cultivate them? Are all tulip noncultivators to be condemned before God by any tulip cultivators?

The arguments are not to be taken seriously. Rather, they parody the horticultural fanaticism that motivates the action of the novel by evoking comparison with the sort of political-evangelical extremism and chauvinism which the argument intertwines with the excessive aesthetic preference of tulip aficionados. The reasoning is supposed to appear specious, in order to dramatize the extent to which the tulip fancier Van Baerle has lost his commonsense moorings in passionate devotion to his ambition to produce a black tulip. In this sense, Dumas' syllogism succeeds admirably. Yet, even as a specimen of distorted logic, the argument works most effectively only insofar as it can readily be reconstructed as an inference that gives every appearance of a line of thought that might occur to a rational though less obsessive mind. It is the application of the argument and the context that surrounds it on which the reader's judgment of its absurdity and the point of Dumas' subtle analogy depends. Conceivably, the argument might be used in earnest by a religious floral zealot.

\section{Heuristics for Charity-Ranked Expansion Choices}

The enthymeme in Dumas' novel, as we have seen, can be reconstructed as a valid inference in several ways. Some of these are reiterative, while others are not. Having explored a few obvious methods of expanding Dumas' enthymeme, what lessons can we draw from the exercise?

The most important moral is the pluralism of choices in expanding enthymemes. An enthymeme can always be reconstructed by reiteration minimally to produce a deductively valid inference. Some enthymemes may even be best or most reasonably or naturally reconstructed by reiteration. This is especially true when an author expresses a conditional inference by detachment in which the conditional itself is deliberately suppressed. But typically there is no need to resort to the more commonly trivializing reiterative ploy when expanding enthymemes in order to satisfy the principle of charity. Enthymemes can be expanded without reiteration, though it is not always clear whether to do so by any available means is always or in other relevant ways necessarily more charitable."

This leads to the second feature in our reconstruction of Dumas' tulip syllogism. The variety of ways in which an enthymeme can be expanded according to the principle of charity suggests a ranking of alternative valid reconstructions to be used in conjunction with the principle of charity in selecting a maximally charitable expansion of an enthymeme for purposes of critical evaluation. The goal of argument analysis for enthymemes should be reconceived, not as an all-or-nothing mechanical procedure for generating complete from incomplete argument statements, nor as a mind-reading exercise, but as an art requiring finesse in applying charity rankings to select a preferred reiterative or nonreiterative expansion. The idea is that an enthymeme is best 
reconstructed by adding hidden or missing argument components in charity-ranked expansions, from the most to the least charitable. The ordering should in turn be guided by the charitable principle that in general we are to prefer conservative nonredundant expansions of enthymemes that result in sound noncircular inferences.

The heuristics of charitable interpretation forbid attributions of propositions that intrinsically contradict the stated assumptions or conclusions of an enthymeme or extrinsically the author's known beliefs, or that are avoidably redundant or questionbegging. With the exception of these limitations, no other possibilities for reconstructing an enthymeme as a valid inference need be excluded. We might further consider a three-tiered hierarchy of charity-ranked expansions. Intrinsically implausible reiterative or nonreiterative expansions are ranked lowest. Reiterations are not forbidden, even when they trivialize inference, but are down-ranked as less charitable than intrinsically plausible nonreiterative interpositions, belonging to the highest tier. Expansions in all three tiers are internally charity-ranked where possible by degree of intrinsic plausibility. When the ranking is accomplished, selection of the preferred expansion for attribution and critical evaluation proceeds from top to bottom, rejecting any in turn if warranted by considerations of external evidence as extrinsically implausible attributions to the enthymeme's author. Comparatively less charitable reconstructions are ordered as of relatively low preference for attribution, and their acceptance can be indefinitely postponed, unless or until all more charitable possibilities are rejected from the initial ranking on grounds of extrinsic implausibility.

Reiterative expansions are not prohibited by the present account as irredeemably uncharitable. In theory, reiterative expansions can be elaborated and then down-ranked for possible acceptance in the absence of a better nonreiterative alternative. If, after eliminating all intrinsically plausible nonreiterative expansions initially ranked above them for reasons of extrinsic implausibility, reiterative expansions might emerge as relatively more charitable than any surviving nonreiterative expansions. The paradigm situation in which a reiterative intrinsically plausible expansion is selected as most charitable because most correct is that in which there is extrinsic justification, such as solid convincing documentation in another of the enthymeme author's statements (like those sometimes fortuitously unearthed by scholars in a private letter, journal entry, or other collateral source), or other solid convincing circumstantial evidence, for supplying the missing reiterative conditional as a hidden assumption the author has deliberately suppressed. This eliminates as extrinsically implausible any nonreiterative expansions previously ranked above it by providing external evidence for the author's intent to suppress the reiterataive conditional. But there are other easily imagined situations in which a reiterative expansion might turn out to be comparatively more charitable than any nonreiterative alternative. ${ }^{12}$

\section{Charity Rankings for a Preferred Expansion of Dumas' Enthymeme}

To see how charity rankings work in actual application, consider again Dumas' tulip syllogism. Charity rankings by type emphasize the multiple purposes that motivate the reconstruction of enthymemes as deductively complete arguments. In practice, as Dumas' argment demonstrates, valid reconstruction of an enthymeme does not always 
produce a single expansion, but often results in several arguments, any of which might reasonably be attributed to the author. These can often appear equally or incommensurably advantageous or disadvantageous in supporting the argument's stated or suppressed conclusions.

For Dumas' syllogism, we have already sketched a sufficient variety of alternative reconstructions to appreciate how the charity rankings proposal might be implemented. The reiterative expansions are not disallowed by this interpretation of the principle of charity, but, because of their obvious trivialization of the resulting argument, are relatively down-ranked. We shall not attribute to Dumas an argument expanded by conditional reiteration from his enthymeme unless we have no better choice. On reflection, we see that luckily there are several less trivial and in this sense more charitable options. If we wish to reconstruct the entire inference from (1) to (5), we have in the propositions already advanced (which are not meant to be exhaustive) the possibility of reconstructing the argument without reiteration either by (1)-(3) or $(1)+(2)+\left[3^{\prime}\right]$ together with $[\mathrm{a}],\left[\mathrm{a}^{*}\right]$, or $\left[\mathrm{b}^{*}\right]$, or with [4'] in place of conclusion (4), followed by an appropriate selection from [b]-[e].

If we weed out combinations in which interposed argument components produce expansions with redundancies, then, in this comparatively simple example, we need only decide how to rank these alternatives:

(i)

$$
(1)-(3)+[a]+[b]-[e] \rightarrow(4)+(5)
$$

$(1)-(3)+\left[a^{*}\right]+[b]-[e] \rightarrow(4)+(5)$

$(1)+(2)+\left[3^{\prime}\right]+[\mathrm{a}]+[\mathrm{b}]-[\mathrm{e}] \rightarrow(4)+(5)$$$
\text { (1) }-(3)+[b-e] \rightarrow[4]+(5)
$$$$
(1)-(3)+[a]+\left[b^{*}\right]+[c]-[e] \rightarrow(4)+(5)
$$$$
(1)-(3)+\left[a^{*}\right]+\left[b^{*}\right]+[c]-[e] \rightarrow(4)+(5)
$$

(viii)

$(1)+(2)+\left[3^{\prime}\right]+\left[b^{*}\right]+[c]-[\mathrm{e}] \rightarrow(4)+(5)$

$(1)-(3)+\left[b^{*}\right]+[c]-[e] \rightarrow\left[4^{\prime}\right]+(5)$

Charity rankings for these eight alternative expansions can be made on the basis of our intuitive heuristic. First, we rank the interposed argument components, [a], $\left[\mathrm{a}^{*}\right],\left[\mathrm{b}^{*}\right],\left[3^{\prime}\right]$, and $\left[4^{\prime}\right]$ (and $[\mathrm{b}]-[\mathrm{e}]$ ), by intrinsic plausibility. We use these rankings to establish an approximate intrinsic plausibility ranking of expansions (i)-(viii), on the basis of the intrinsic plausibility of the interposed argument components they contain, for each of the three tiers of expansion types, from most to least charitable. The method requires that we begin with intrinsically plausible nonreiterative expansions, and proceed to intrinsically plausible reiterative expansions, and finally to intrinsically implausible reiterative expansions. With this ordering in place, we then eliminate expansions objectionable on grounds of extrinsic implausibility (if any), progressively exposing for consideration charity-down-ranked alternatives, including reiterative expansions, originally occurring lower in rank.

That different critics might plausibility-rank expansion components or charityrank the expansions in different ways is no criticism of the method. Evaluative differences of this kind will evidently result in incompatible attributions of expansions to authors of the same enthymemes at the hands of different interpreters. But this is bound to happen anyway whenever critics from different perspectives and with differ- 
ent theoretical and methodological commitments apply informal methods to reasoning in ordinary language. No unique infallible heuristics for expanding and selecting from among alternative expansions of an enthymeme should realistically be expected, just as no unique infallible heuristics should realistically be expected in proposing any single charitable enthymeme expansion. The purpose of charity ranking is only to provide a better model for selecting among alternative valid reconstructions of enthymemes however these are arrived at, not a foolproof mechanical algorithm for determining the most charitable expansion in any absolute sense. It is easy to see that nothing more definite should be aimed at. For if one charitable critic accepts a certain proposition, it will be charitable for that critic to expand an enthyeme by interposing the proposition or another consistent with it, while another equally charitable critic who does not accept the proposition cannot always charitably do so. The present proposal is intended as no more than a useful structure for comparative evaluation of charitable reiterative and nonreiterative reconstructions once we have them and by whatever means we find or devise them, and as such allows as charitable different interpretations reflecting different value commitments to the distinct and potentially incommensurable desiderata prescribed by charity. ${ }^{13}$

My own intrinsic plausibility ranking for the expansion components or implicit or suppressed assumptions and conclusions in the Dumas enthymeme, from most to least intrinsically plausible (and for simplicity ignoring $[\mathrm{b}]-[\mathrm{e}]$ ), is: $\left[4^{\prime}\right]-\left[\mathrm{a}^{*}\right]-[\mathrm{a}]-$ $\left[3^{\prime}\right]-\left[b^{*}\right]$. From this, we can see that the three-tiered charity ranking of expansions, if each were based on just one of these components (though there are also more complex combinations), would be: $\left[4^{\prime}\right]-[a]-\left[3^{\prime}\right]-\left[a^{*}\right]-\left[b^{*}\right]$.

I find $\left[b^{*}\right]$ the least plausible because it attaches without further rationale what I hope almost anyone would regard as the normatively most outrageous moral consequence to a set of descriptive conditions about subjective aesthetic judgments and religious sentiments. I rank [3'] next lowest, because I think that if we grant the legitimacy of subjective aesthetic judgment required to uphold the proposition, then we should also be able to provide at least a crude standard of measure for a tulip's beauty (number of persons who prefer it, intensity of preference over other kinds of flowers, etc.). In that case, hyperbole aside, the beauty of tulips is not intrinsically plausibly regarded as beyond all measure. Component [a] is intrinsically implausible for much the same reason. Yet I find it is less intrinsically implausible than [3'], because, by attributing immeasurable beauty only to whatever flower is the most beautiful, it is not freighted with the additional burden of maintaining against the equally legitimate subjective aesthetic judgment of naysayers that tulips in particular are beautiful beyond measure. Proposition $\left[\mathrm{a}^{*}\right]$ again is less implausible than [a] in my opinion because $\left[\mathrm{a}^{*}\right]$ is merely conditional, and commits itself only to the position that God is offended beyond measure by those who despise tulips only if all three conditions of [ $\left.\mathrm{a}^{*}\right]$ hold. Its difficulty occurs in the disproportionate leap by which God is offended beyond measure not by those who despise the tulip as a flower beautiful beyond measure, but merely as the most beautiful flower. I regard [4'] as having the highest plausibility on the grounds that it confines offense to God by flower despisers within the measurable, and preserves a sane proportionality between the exact degree of offense to God occasioned by the exact degree of beauty of the flower the offender happens to despise. 
If this is a reasonable plausibility ranking for expansion components, it has the following consequences for the charity ranking of the eight expansions, according to the heuristic ranking procedure described. From most to least charitable, the alternative reconstructions of Dumas' enthymeme on this basis are (inexactly) ranked in this (approximate) way: (iv)-(i) - (iii)-(ii)-(viii)-(v)-(vii)-(vi). ${ }^{14}$ There is, we shall assume, no extrinsic justification for rejecting the top-ranked choice. Hence, the preferred most charitable expansion of Dumas' enthymeme on this evaluation is argument (iv). It is this inference:

1.To despise flowers is to offend God.

2. The more beautiful a flower is, the more one offends God by despising it.

3. The tulip is the most beautiful of all flowers.

[b. Those who cultivate tulips (in Holland, France, Portugal, etc.) do not despise tulips.]

[c. Those who do not cultivate tulips (in the rest of the world) despise tulips.]

[d. Those who despise tulips do not base their salvation on the cultivation of tulips.]

[e. Those who do not offend God beyond measure [to the highest degree possible within the range of degrees to which God can be offended by those who despise flowers] are entitled to put under ban and condemn as schismatics and heretics deserving of death all those who offend God beyond measure [to the highest degree possible within the range of degrees to which God can be offended by those who despise flowers].]

[4'. Whoever despises tulips offends God to the highest degree possible within the range of degrees to which God can be offended by those who despise flowers.]

5. Those who cultivate tulips are entitled to put under ban and condemn as schismatics and heretics deserving of death all those who do not base their salvation on the cultivation of tulips.

\section{Conclusion}

The model is pluralistic in encouraging critics to experiment with a number of different expansions. These may range from the least controversial or problematic to the most trivializing and least charitable. In particular, unlike standard expansion heuristics, the proposal does not forbid satisfying the principle of charity by conditional reiteration; it merely ranks reiteration so low in charity among alternative expansions that expanding an enthymeme by reiteration is made, as (other things being equal) it should be, a rare exception justified only by extrinsic plausibility considerations after the elimination of all intrinsically plausible nonreiterative alternatives.

But because of its trivialization of valid deductive inference, in the absence of external evidence to the effect that the author intends to express a conditional inference with the conditional implicit or suppressed, the proposal rightly regards reitera- 
tion as a least charitable interpretation of last resort, and most generally ranks it below other available intrinsically plausible expansions. The model, unlike some of its competitors, requires the critic to consider many possible interpretations, and to evaluate the argumentative strengths and weaknesses of each ranked choice among the possible expansions of an enthymeme. Finally, charity ranking invites inquiry into what may otherwise be unexplored possibilities of interpretation, by requiring as part of the reconstruction process a specific procedural consideration of the variety of reiterative and nonreiterative arguments an author may have intended to communicate in advancing an enthymeme..$^{15}$

\section{Notes}

'A detailed history of alternative formulations of the principle of charity with their theoretical implications is given by Ralph H. Johnson, "Charity Begins at Home", Informal Logic Newsletter, 3, 1981, pp. 4-9. Johnson traces appeals to concepts of charitable interpetation from Stephen Thomas, Practical Reasoning in Natural Language (Englewood Cliffs: Prentice Hall, Inc., 1973), p. 9 (see also the second edition, 1981, pp. 15-16, 79), to Robert Baum, Logic, second edition (New York: Holt, Rinehart and Winston, Inc., 1981), pp. 94-95, 106-107, 122, 240, 395, to Michael Scriven's insightful treatment in Reasoning (New York: Random House, 1980 ), pp. 71-72.

${ }^{2}$ That enthymemes as incomplete inferences are necessarily invalid, and hence that they require expansion for charitable evaluation, is emphasized by Alan Ross Anderson and Nuel D. Belnap in their classic paper, "Enthymemes", The Journal of Philosophy, 58, 1961, pp. 713-723. See also Rolf George, "Enthymematic Consequence", American Philosophical Quarterly, 9, 1972, p. 113: "Arguments of this sort [enthymemes], though formally invalid, must be allowed to have some merit". Roy A. Sorensen, "Are Enthymemes Arguments?", Notre Dame Journal of Formal Logic, 29, 1988, p, 155: "Although there is disagreement as to how 'enthymeme' is to be defined, there is a consensus that all enthymemes are invalid arguments." Douglas N. Walton, "Enthymemes", Logique et Analyse, 26, 1983, p. 395: "The doctrine of enthymemes would seem to suggest the following rule: always add the weakest premiss needed to make the argument valid."

${ }^{3}$ Michael Burke, "Unstated Premises", Informal Logic, 2-3, 1985, p. 108: "There is a problem. Initially to over-simplify, the problem is that the most plausible candidate [for a suppressed premise in the charitable expansion of an enthymeme] will always be the weakest candidate And if ' $P$ ' abbreviates the conjunction of the premises of some deductively invalid argument, and ' $C$ ' its conclusion, the weakest validating proposition is expressed simply by 'If $P$ then $C^{\prime}$...I will call this the 'reiterative' candidate, since several writers remark that it merely 'reiterates' the arguer's claim that the conclusion follows from the premises."

"See Gerald J. Massey, "Are There Any Good Arguments that Bad Arguments are Bad?", Philosophy in Context, 4, 1975, p. 67: "...we can insure that [expanding enthymemes according to the principle of charity] will never reject as invalid an argument that we deem valid, for suitable 'suppressed' premisses are always forthcoming. If we can't think of a more apt suppressed premiss for an argument we like, we can always choose the conditional whose consequent is the argument's conclusion and whose antecedent is the conjunction of its premisses...the problem with [the principle of charity] is that it works too well. Given any argument one can come up with a "suppressed' premiss that makes it patently valid, i.e., that turns it into an argument that can be easily paraphrased into a valid argument form of some extant logical system."

"Charitable expansions of enthymemes involving conditional reiteration are discussed by Tomis Kapitan, "A Definition of Enthymematic Consequence", International Logic Review, 11, 1980, 
pp. 58-59.

'David Hitchcock, "Enthymematic Arguments", Informal Logic, 7, 1985, p. 89: "Since our purpose is evaluation, we should look for an assumption on which the argument depends, regardless of whether the arguer had such an assumption in mind, rather than an assumption the author had in mind, which may be neither necessary nor sufficient for the conclusion's following from the premiss(es)."

${ }^{7}$ For general philosophical considerations against the appeal to an author's intentions in giving useful interpretations, see William K. Wimsatt, Jr. and Monroe Beardsley, "The Intentional Fallacy", in Wimsatt, The Verbal Icon (Lexington: University of Kentucky Press, 1954), Chapter 1; rpt. in Joseph Margolis, editor, Philosophy Looks at the Arts: Contemporary Readings in Aesthetics, third edition (Philadelphia: Temple University Press, 1987), pp. 367-380. I find it more satisfyfing to work toward reconstructions that do not try to speak for an author's intentions from a third-person standpoint, but that make responsible critical use of whatever external evidence can reasonably be offered in identifying an author's likely intentions. This serves minimally in evaluating the argumentative or other dialectical advantages and disadvantages of the various more complete arguments an author may have intended in advancing an enthymeme. "Walton, "Enthymemes", p. 396: “...the well-known principle of charity recommends adding the missing premisses that the arguer most plausibly had in mind from what we know of his position and the context of argument. But how to select the 'most plausible' proposition from the multitude of sufficient candidates available? I don't see any obviously correct general logical principle for carrying out such a procedure." An attempt to provide informal criteria for selecting preferable expansions of enthymemes is made by Mike Donn, "Help in Finding Missing Premises", Teaching Philosophy, 13, 1990, pp. 159-164; Robert H. Ennis, "Identifying Implicit Assumptions", Synthese, 51, 1982, pp. 61-86; Thomas Schwartz, "Logic as a Liberal Art", Teaching Philosophy, 4, 1981, pp. 231-247. See also Gerald M. Nosich, Reasons and Arguments (Belmont: Wadsworth Publishing Company, 1982), pp. 19, 142, 160, 216-224. Hitchcock, Critical Thinking: A Guide to Evaluating Information (Toronto: Methuen, 1983), pp. 73-77. John Nolt, Informal Logic: Possible Worlds and Imagination (New York: McGrawHill, 1984), pp. 97-140. David Kelley, The Art of Reasoning with Symbolic Logic, expanded edition (New York: W.W. Norton \& Company, 1990), pp. 211-212. Trudy Govier, A Practical Study of Argument, third edition (Belmont: Wadsworth Publishing Company, 1991), pp. 42-44, 49-55.

'A lexandre Dumas, The Black Tulip, translated by Fayette Robinson (Boston: The C.T. Brainard Publishing Company, 1910), pp. 54-55. Inexplicably, except perhaps for reasons of piety, this passage does not appear in all English translations of the text. The most recent edition by David Coward (Oxford University Press, 1993), which reprints the Franz Demmler translation of 1854, omits the tulip syllogism entirely. See Coward's 'Note on the Text', pp. xxii-xxiii, for a partial history of abridgements of Dumas' first French version of La Tulipe noire, beginning with the pirated Belgian editions of 1850. The point of Van Baerle's excessive fondness for tulips is epitomized in the Demmler translation when Dumas proclaims in Chapter 6, 'The Hatred of a Tulip-Fancier', p. 52: "But to kill a tulip was a horrible crime in the eyes of a genuine tulip-fancier; as to killing a man, it would not have mattered so very much."

${ }^{10}$ It might be objected that God's offense is beyond measure anyway for obvious metaphysical criteriological reasons. But then the conclusion of Dumas' syllogism by which God's immeasurable offense induced by the most beautiful flower's being despised loses much of its significance. We can then equally conclude that God's offense is beyond measure when a daisy or daffodil is despised, on the grounds that all of God's properties are necessarily beyond measure. It seems preferable, as a result, to interpret Dumas' syllogism as committed to a direct positive proportion between the degree of a flower's beauty and the degree of God's offense 
induced by the flower's being despised. The conclusion that God is offended beyond measure by those who despise tulips, the most beautiful flowers, if their beauty is not proportionately regarded also as beyond measure, is then best understood merely as a hyperbolic rhetorical bouquet.

"Nelson Pole, "Enthymemes in Propositional Logic", Teaching Philosophy, 3, 1980, p. 327 : "In an enthymeme it is a good principle to avoid placing content from the conclusion into the missing premise unless no other alternative is available." This heuristic quite reasonably falls short of prohibiting reiterative expansions of enthymemes, while down-ranking it in favor of more charitable possibilities.

"See James Gough and Christopher Tindale, "“'Hidden' or 'Missing' Premisses", Informal Logic, 2-3, 1985, p. 102: "On our reading...premises are extracted from and not injected into or added onto the text to make an argument. Hidden premises unlike missing premises are already there, not added to what is there to make something out of what is there. Advice telling us to give a piece of text a "fair' reading is not the same as advice telling us to construct the best possible argument out of the limited material given in the text." This commendable approach nevertheless seems unduly limited to the resources of an enthymeme's immediate context, with no provision for consulting collateral external evidence in support of the extrinsic plausibility of a proposed expansion.

${ }^{13}$ The choice from among alternatives of a heuristically preferred enthymeme expansion cannot be formal, mechanical, or algorithmic. There is in the first place no such method for producing alternative expansions. Nor is there fixed and final agreement about how to weight the potentially incommensurable requirements of charitable evaluation. Thus, there can be no settled fully general satisfactory procedure for choosing a circular but unsound expansion of an enthymeme over a sound but noncircular expansion, or the reverse. Other stubborn disputes center on whether charitable reconstruction should permit or forbid the revision of an argument's explicitly stated assumptions or conclusions. See, for example, Burke, "Unstated Premises", p. 108: "One justly popular criterion is what I will call "preservation", according to which we should try to preserve the role of the stated premises." This rationale presumably applies as well to an enthymeme's stated conclusions. But there are exceptions, as the proposed interpretation of Dumas' tulip syllogism suggests, in which charity might also demand revision or replacement of explicitly stated argument components, whether assumptions or conclusions.

${ }^{14}$ The proposed theoretical analysis of ideal charity rankings among alternative valid reconstructions of enthymemes is not necessarily intended as a practical mental or pencil-andpaper method of choosing the most charitable expansion of an enthymeme. Yet it could be used in this way, in which case its apparent cumbersomeness must be balanced against the importance of our need for a more exact charity ranking than we can have intuitively with less effort. The payoff for actually adopting such a method as a more or less step-by-step procedure might at least sometimes be worth the trouble, if, as 1 have argued, charitable evaluations of enthymemes are not only morally but epistemically justified.

${ }^{15}$ An earlier version of this essay was presented in a special colloquium session on enthymemes at the Third International Conference on Argumentation, International Society for the Study of Argumentation (ISSA), University of Amsterdam, Amsterdam, The Netherlands, June 24, 1994. 